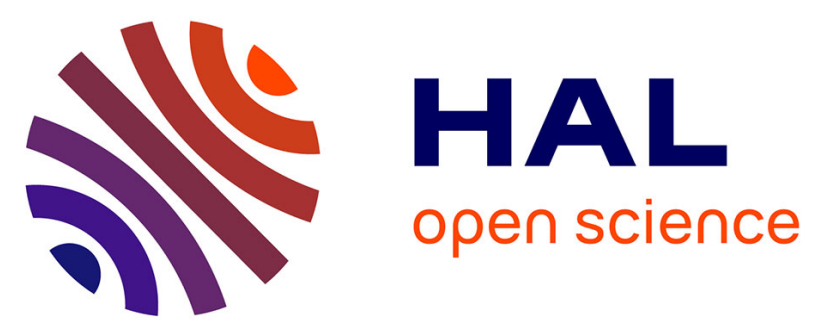

\title{
Dynamic Model of Li-Ion Batteries Incorporating Electrothermal and Ageing Aspects for Electric Vehicle Applications
}

Tedjani Mesbahi, Nassim Rizoug, Patrick Bartholomeus, Redha Sadoun, Fouad Khenfri, Philippe Le Moigne

\section{To cite this version:}

Tedjani Mesbahi, Nassim Rizoug, Patrick Bartholomeus, Redha Sadoun, Fouad Khenfri, et al.. Dynamic Model of Li-Ion Batteries Incorporating Electrothermal and Ageing Aspects for Electric Vehicle Applications. IEEE Transactions on Industrial Electronics, 2018, 65 (2), pp.1298 - 1305. 10.1109/TIE.2017.2714118 . hal-01887922

\section{HAL Id: hal-01887922 \\ https://hal.science/hal-01887922}

Submitted on 4 Oct 2018

HAL is a multi-disciplinary open access archive for the deposit and dissemination of scientific research documents, whether they are published or not. The documents may come from teaching and research institutions in France or abroad, or from public or private research centers.
L'archive ouverte pluridisciplinaire HAL, est destinée au dépôt et à la diffusion de documents scientifiques de niveau recherche, publiés ou non, émanant des établissements d'enseignement et de recherche français ou étrangers, des laboratoires publics ou privés. 


\title{
Dynamic model of Li-Ion Batteries Incorporating Electrothermal and Ageing Aspects For Electric Vehicle Applications
}

\author{
MESBAHI Tedjani, RIZOUG Nassim, BARTHOLOMEUS Patrick, SADOUN Redha, \\ KHENFRI Fouad, LE MOIGNE Philippe
}

\begin{abstract}
In this paper, a dynamic model of Li-ion batteries incorporating electrothermal and ageing aspects is proposed for electric vehicle applications. The main goal of the proposed model is to be both simple and sufficiently representative of the physical phenomena occurring in a battery cell. These two features allow for using this model as an evaluation tool of electric vehicle performances under different operational and environmental conditions. The developed model is based on an equivalent circuit diagram coupled with a thermal circuit and a semi-empirical ageing equation. Identification of parameters in the dynamic model is conducted by measurement tests in timedomain, which uses a hybrid Particle Swarm-Nelder-Mead optimization algorithm to achieve excellent prediction over the whole applicable current and state of charge ranges. The validation results show that the proposed model is able to simulate the dynamic interaction between the battery ageing and the thermal as well as electric behavior with sufficient accuracy in the range tested.
\end{abstract}

Index Terms - Electric vehicle, Li-Ion Batteries, dynamic model, ageing behavior, State of charge (SOC).

\section{INTRODUCTION}

$\mathrm{T}$ HE vast majority of the one billion passenger vehicles worldwide are powered by fuel derived from crude oil [1]. By 2050, this number will have increased to 2.5 billion [2], [3]. This upward trend represents both a challenge and an opportunity to capitalize on novel vehicle technologies, and in the process, reap substantial economic development benefits [1], [2]. In a world where energy derived from fossil fuels is the leading cause of greenhouse gas emissions which are responsible for the rapid changes to our atmosphere, an alternative source of transportation energy - electricity - is not only a smart investment, but as some would say, it is an inevitable one [1], [2]. Since few years, manufacturers in the transportation industry have been started an unprecedented technological change. The voice of progress is among others related to the partial or total vehicle electrification [4], [5]. These solutions have many advantages compared with vehicles running only on fuel and using internal combustion engine [4], [6]. The development of hybrid and electric vehicles in recent years has increased the use of batteries and converted them into one of the most critical elements in the automobile sector [7].
The technology chosen for the new generation of hybrid and electric vehicles is based on the Li-ion solution [8]. This technology provides up to a $175 \%$ improvement in energy density over regular $\mathrm{NiH} 2$ batteries and offers others advantages, including high voltage, lightweight design, low self-discharging, and long cycle life [9], [10], [11].

A driving factor for Li-ion battery modeling is the demand from system level design and simulation in electric vehicle applications [12]. Recently, several battery models are being introduced and studied in automobile applications. They can be classified as electrochemical, mathematical, electrical, and polynomial [13], [14]. All these models have the ability to predict the performance of the battery, but with different levels of simplicity and accuracy [15]. Considerable effort has been put into the development of high fidelity battery models that accurately predict voltage given the input current [16]. However, the change of electric model parameters according to the ageing of the battery and its operation temperature requires a dynamic model with sufficiently fine representations of electrical, thermal and ageing behaviors, which predicts the performance of the battery at different operating conditions.

The present paper proposes a dynamic model of Li-ion batteries that integrates on the same algorithm, the electrical, thermal and ageing aspects of one battery cell. This solution helps to analyze the performances of the electric vehicle by accurately simulating the electrothermal processes occurring in Li-ion battery. As a result, it allows us to avoid the errors accumulation that could lead to a drift in simulation and gives the performances degradation in terms of the capacity power fade and the internal resistance over long periods with a good trade-off between accuracy level and calculation time.

The rest of this paper is organized as follows: The dynamic model of Li-ion battery is discussed in Section II. Section III presents the design of the experiment. The obtained results and discussion are presented in Section IV to evaluate the feasibility and eligibility of Li-ion battery model. Section V, finally concludes the paper and present future work tracks.

\section{DyNAmic Model Of Li-ION BATtery}

The battery is a complex electrochemical system which is both nonlinear and non-stationary [17], [18]. This nonlinearity of the battery is due to the fact that the relationship between 
the applied current and the output voltage cannot be expressed by a linear relationship. However, the battery is considered as a non-stationary system because the characteristics of its internal electrical parameters are variable during a cycle of charge / discharge as well as during the lifetime cycle [16], [17]. As a result, static and dynamic electrochemical phenomena act together at each electrode of the battery. For this reason, many researchers are working on the development of fine and precise descriptions of the Li-ion battery behaviors, which take into account three dominant variables voltage, temperature and ageing [19], [20], [21], [22], [23].

\section{A. Proposed battery model}

In our study, the dynamic battery model must take into account the specificities of the Li-ion technology and electric vehicle application. Moreover, it must be simple enough and at the same time be able to accurately simulate the behavior of the Li-ion battery in order to integrate easily into the overall vehicle model. The proposed model consists of three main parts:

- The electric model based on an equivalent circuit, which used to represent the link between the applied current, the output voltage, and the SOC of the battery.

- The thermal model based on constant lumped elements circuit allows access to the internal temperature of the battery. It varies depending on the ambient temperature and internal power loss.

- The ageing model based on a semi-empirical equation, which used to correct the values of internal electrical parameters, with a feedback of new values of the battery energy capacity (in ampere-hours) and the equivalent series resistance each cycle of charge / discharge.

Fig. 1 shows the dynamic battery model, which take into account three aspects voltage, temperature, and ageing.

The equivalent circuit used in this paper is an extension to the Thevenin classical model which is suitable for electric power applications [24]. This model offers an excellent representation of the static and dynamic electrochemical phenomena, such as the distribution of reactivity at the electrode, the interfacial impedance, the charge transfer, the diffusion and the electron and ion migration resistance, at a lower computational effort [17], [25]. This model consists in an open-circuit voltage (denoted OCV) associated with a nonlinear complex impedance composed of three elements. The $V_{O C V}$ changes according to SOC by the following nonlinear equation [15]:

$V_{O C V}(S O C)=x_{1}+x_{2} \cdot e^{\left(x_{3} \cdot(1-s o c)\right)}+x_{4} \cdot e^{\left(x_{5} \cdot s o c\right)}+$ $x_{6} \cdot e^{\left(x_{7} \cdot(1-s o c)^{2}\right)}+x_{8} \cdot e^{\left(x_{9} \cdot(s o c)^{2}\right)}+x_{10} \cdot e^{\left(x_{11} \cdot(1-s o c)^{3}\right)}+$ $x_{12} \cdot e^{\left(x_{13} \cdot(\operatorname{soc})^{3}\right)}$

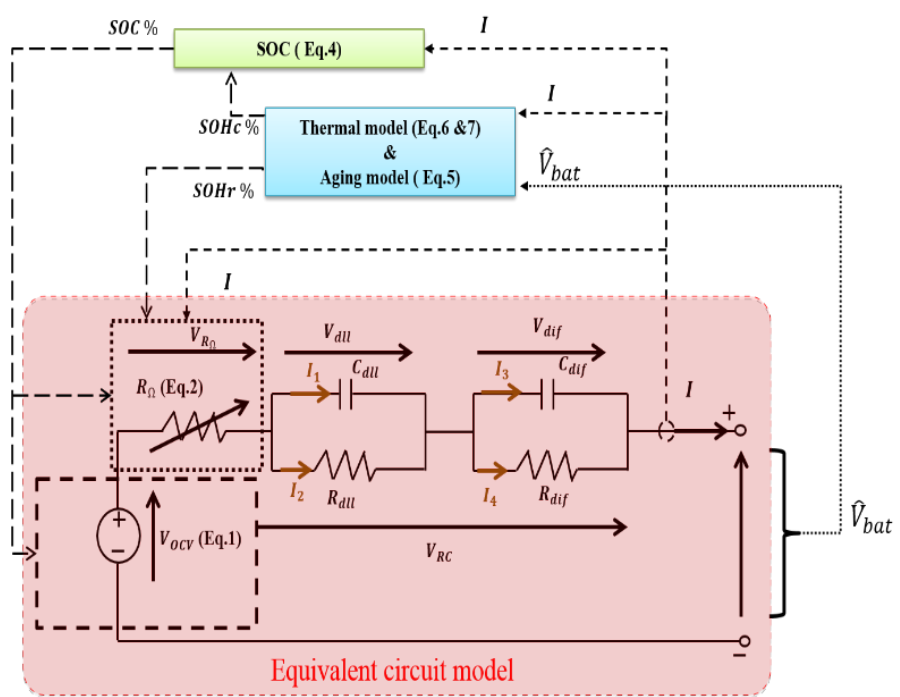

Fig. 1. Dynamic battery model.

Where $x_{1 \ldots 13}$ are optimal parameters chosen to make the battery model fits the experimental data very well. The computing method for these parameters of battery model will be defined below.

The first element of the battery impedance is a resistance $R_{\Omega}$ to model the global ohmic behavior of the battery including metallic connection between poles and electrodes, conductivity of metallic contacts, intercell connections, electrode material and the bulk electrolyte [15], [17]. This equivalent series resistance is related to the SOC and the current sign to be more accurate in capturing the transient behavior of the Li-ion battery [15],[26]:

$R_{\Omega}=S O H_{r} \cdot \frac{x_{14}}{\sqrt{\operatorname{soc}+x_{15} \cdot \operatorname{soc} \cdot \operatorname{sign}\left(I_{b}\right)}}$

Where $I_{b}$ is the instantaneous current of battery (positive for discharge and negative for charge). $x_{14}$ and $x_{15}$ are optimal parameters of equivalent series resistance $\mathrm{R}_{\Omega}$. The increase of internal resistance during battery operation is reported as the indication of the resistance State Of Health $\left(\mathrm{SOH}_{r}\right)$.

This model includes also two pairs of capacitance and resistance $R_{d l l} C_{d l l}$ and $R_{d i f} C_{d i f}$, which makes the model more accurate in capturing the transient behavior (charge transfer and diffusion phenomenon) of the Li-battery [15], [27]. The voltage corresponds to two pairs $R_{d l l} C_{d l l}$ and $R_{d i f} C_{d i f}$ circuits is given by [15], [17]:

$\left\{\begin{array}{l}V_{R C}=V_{d l l}+V_{d i f} \\ V_{d l l}(s)=I_{2}(s) \cdot R_{d l l}=\frac{1}{1+s R_{d l l} C_{d l l}} \cdot \frac{I \cdot R_{d l l}}{s} \\ V_{d i f}(s)=I_{4}(s) \cdot R_{d i f}=\frac{1}{1+s R_{d i f} C_{d i f}} \cdot \frac{I R_{d i f}}{s} \\ I_{1}+I_{2}=I_{3}+I_{4}=I\end{array}\right.$

Where the time constants for $R_{d l l} C_{d l l}$ and $R_{d i f} C_{d i f}$ circuits are $\tau_{d l l}=R_{d l l} C_{d l l}$ and $\tau_{d i f}=R_{d i f} C_{d i f}$ respectively.

The Coulomb counting (ampere-hour counting) method is widely used in battery management systems of electric 
vehicles [21]. It is easy to use and fast in computation, which the time integral of the battery current is considered as a direct SOC indication as follows [15], [23]:

$S O C=100 .\left(S O C_{i n t}-\frac{1}{S O H_{c} \cdot C_{n}} \int \eta I d t\right)$

Where $S O C_{\text {int }}$ is the initial value of the SOC, $C_{n}$ represents the nominal capacity of the battery (in ampere-hours), $\eta$ is the Coulombic efficiency $\left(\eta \simeq 1\right.$ for Li-ion batteries). $S O H_{c}$ represents the ratio of the amount of charge that can be drawn from a new battery to the used battery [23].

The capacity and resistance state of health's $\left(\mathrm{SOH}_{c} \& \mathrm{SOH}_{r}\right)$ are estimated by battery ageing model [20] :

$$
\left\{\begin{array}{c}
S^{\prime} O H_{c}=C_{i n t} \cdot\left[1+c_{a_{-} c} \cdot \sqrt{t}\left(c_{T_{-} c}^{\frac{T-T_{0}}{\Delta T}} \cdot c_{V_{-} c}^{\frac{V-V_{0}}{\Delta V}}\right]\right. \\
S O H_{r}=R_{\Omega_{-} i n t} \cdot\left[1+c_{a_{-} r} \cdot \sqrt{t}\left(c_{T_{-} r}^{\frac{T-T_{0}}{\Delta T}} \cdot c_{V_{-} r}^{\frac{V-V_{0}}{\Delta V}}\right]\right.
\end{array}\right.
$$

Where $R_{\Omega_{-i n t}}, C_{i n t}$ are the initial values of the equivalent series resistance $R_{\Omega}$ and the battery energy capacity, respectively. The parameters $\mathrm{V}$ and $\mathrm{T}$ are the average voltage and temperature of the battery cell, respectively. The related reference parameters $T_{0}, V_{0}, \Delta T$ and $\Delta V$ can be chosen according to battery technology and test conditions. In addition, $c_{a}, c_{T}$ and $c_{V}$ are acceleration factors describing the rate of ageing at reference conditions of the time, temperature and voltage [20].

It is necessary to estimate the internal temperature of the Liion battery, its voltage, and its current characteristics to know the evolution of the battery energy capacity (in ampere-hours) and the equivalent series resistance $\mathrm{R}_{\Omega}$. This is justified by the fact that the battery lifetime depends strongly on temperature and voltage, the ageing model receives temperature and voltage calculated by the electrothermal model in each time step [20].

The thermal model using constant lumped elements circuit will be utilized to estimate the internal temperature of one battery cell. Based on the temperature estimation, the heat distribution of the battery can be updated in each time step. The heat generated by a battery cell is the combination of the heat generation due to the electrochemical reactions and drop power losses of the equivalent series resistance within the cell as a function of the electric current and SOC. In our model, a thermal equivalent circuit based on one thermal resistance and one heat capacitance delivers the heat power. The latter can be defined according to the energy conservation law [28] :

$$
R_{t h}=\frac{1}{\frac{d Q_{g e n}}{d t}}\left(T_{\text {steady-state }}-T_{a m b}\right)
$$

Where $\frac{d Q_{g e n}}{d t}$ is the heat generation rate (power losses). The environment around the battery is assumed to have an infinite heat capacitance and the ambient temperature $T_{a m b}$ can be considered constant.

The thermal resistance $R_{t h}$, models the heat transfer inside the battery cell and the heat transfer through convection between the cell and the surrounding environment (adiabatic fence). This resistance can be defined as a nonlinear function changes according to the battery SOC:

$$
R_{t h}=a_{1}+a_{2} \cdot \operatorname{soc}^{4}
$$

Where $a_{1}$ and $a_{2}$ are optimal parameters chosen to make the thermal model fits the experimental data very well.

If the thermal resistance $R_{t h}$ of the battery cell is known, the heat capacity (thermal capacitance) $C_{t h}$ can be expressed as follow:

$$
\tau=R_{t h} C_{t h}
$$

With $\tau$ is the thermal time constant.

\section{B. Parameters identification of dynamic Li-ion battery model}

The identification of battery model parameters based on equivalent circuits can be done either by specific tests, or by electrochemical impedance spectroscopy (frequency characterization), or by temporal identification using chronopotentiometry [29]. Nevertheless, the temporal characterization method using current profiles close to the actual use of the battery is widely employed in electric power applications [30]. In this paper, the temporal identification method based on a hybrid Particle Swarm-Nelder-Mead (PSO-NM) optimization algorithm is used to identify the parameters of the Li-ion battery model. This improved method of the characterization is based on the use of equivalent current profiles applied to the traction battery in real applications. This solution enables us to evaluate directly the impedance of the battery in real time and at several working points, without performing additional tests [15]. The common objective function used in electric, thermal, and ageing characterization of the Li-ion battery is given by:

$\left\{\begin{array}{c}\min _{X}\{F(X)\} \\ X_{\text {min }} \leq X \leq X_{\text {max }} \\ F(X)=\sum_{i=1}^{n}\left(\widehat{M}_{b a t / s c}-M_{\text {bat } / s c}\right)^{2}+\sum_{i=1}^{n}\left|\widehat{M}_{b a t / s c}-M_{b a t / s c}\right|\end{array}\right.$

Where $\mathrm{X}=\left\{x_{1}, x_{2} \ldots \ldots x_{n}\right\}$ is an optimization parameter vector. $X_{\min }, X_{\max }$ are parameter bounds of research space. $\widehat{M}_{b a t / s c}$ can also take the simulation value of the battery voltage, temperature, equivalent series resistance, or energy capacity. However, $M_{b a t / s c}$ can be the measurement value of the battery voltage, temperature, equivalent series resistance, or energy capacity.

This optimization criterion (objective function) is based on the minimization of both Squares Error Sum (SSE) and Absolute Error Value (AEV) between the experimental data and the model-based simulation result. The used algorithm of optimization is made-up of a modified particle swarm optimization algorithm (PSO), aimed to identify the most promising areas, and a Nelder-Mead simplex algorithm (NM) for performing a local search within these areas [8], [15], [31].

This ability to search the overall optimal solution and to avoid getting locked in local optima allows us to reach the 
identification goal, which makes the dynamic Li-ion battery model fits the experimental data very well.

\section{DESIGN OF EXPERIMENT}

To identify and validate the dynamic battery model and verify its performances in an electric vehicle application, a test system has been designed. The battery used in this test was a 40Ah prismatic Li-ion pouch cell with NMC cathode material and graphitic anode, which is commercialized by Dow Kokam manufacture under the references HED-SLPB90216216 [32]. The nominal, maximum, and cutoff voltages of the battery under study are $3.7,4.2$, and $2.7 \mathrm{~V}$, respectively.

\section{A. Simplification of the real current profile}

An urban electric vehicle (Bolloré Bluecar) has been chosen for this study. The characteristics of selected vehicle are described in detail in [33], [34].

In order to simplify the real current profile requested by the electric vehicle, we have developed in our laboratory a heuristic method based on constraints classification in intensity levels. It aims to reduce the cycling time while preserving the most important characteristics for test profiles such that the maximum value of the current and the amount of exchange charges.

Before applying this constraints classification, the common ARTEMIS driving cycle is chosen for testing the urban electric vehicle powered by the Li-ion battery [35]. This cycle consists of both urban and road driving parts with an average speed of about $7,5 \mathrm{~km} / \mathrm{h}$ and $110,7 \mathrm{~km} / \mathrm{h}$, respectively. The combination of urban and road cycles can simulate a rolling distance of $22 \mathrm{~km}$ over a period of about 34 minutes [34], [35]. In order to achieve a total driving range of close to $154 \mathrm{~km}$, the ARTEMIS driving cycle has been repeated 7 times with a roadway slope of $2.5 \%$. Based on these specifications and the developed simulator of electric urban vehicle, the real current profile of the Li-ion battery can be carried out.

To explain the heuristic method based on constraints classification, we use the simplified profile of Fig. 2.

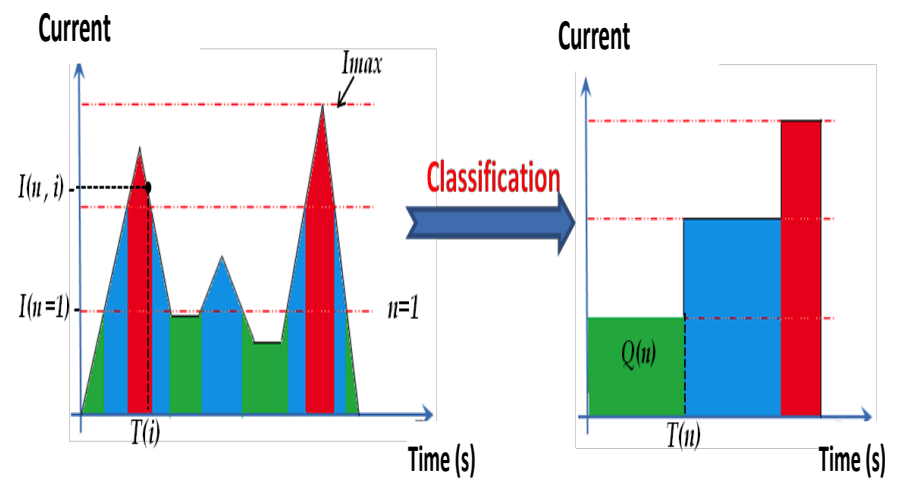

Fig. 2. Simplified constraints (power, energy) applied to battery cells. (A) Real current. (B) Current after simplification and classification.

In the first step, the current profile is divided into $(\mathrm{N})$ levels, which the value of each level $\left(\mathrm{I}_{\mathrm{n}}\right)$ is described by:

$\mathrm{I}_{\mathrm{n}}=\frac{\mathrm{I}_{\max } \cdot \mathrm{n}}{\mathrm{N}}$
Where $n$ is the index of the level, $n=\{1 . \ldots N\}$. In this example $\mathrm{N}=3 . \mathrm{I}_{\max }$ is the maximum value of charging or discharging currents.

Thereafter, all the current values are grouped into $\mathrm{N}$ classes and each class contains $P_{n}$ elements (elements are the instantaneous values of current).

$\left[\begin{array}{cccc}\mathrm{I}_{11} & \mathrm{I}_{12} & \ldots & \mathrm{I}_{1 \mathrm{P}_{1}} \\ \mathrm{I}_{21} & \vdots & \vdots & \vdots \\ \vdots & \vdots & \mathrm{I}_{\mathrm{ni}} & \mathrm{I}_{\mathrm{nP}_{\mathrm{n}}} \\ \mathrm{I}_{\mathrm{N} 1} & \mathrm{I}_{\mathrm{N} 2} & \ldots & \mathrm{I}_{\mathrm{NP}_{\mathrm{N}}}\end{array}\right]$

For each individual $i$ belongs to the class $n$, it is necessary that the current intensity I (n. i) satisfies the following condition:

$\mathrm{I}_{\mathrm{n}-1}<I(\mathrm{n} . \mathrm{i}) \leq \mathrm{I}_{\mathrm{n}}$

To finish, all the constraints generated by the current values $\mathrm{I}(\mathrm{n}$. Pn) of the level $\mathrm{n}$ is represented by the maximum value of current $I_{n}$ during time $T(n)$, as shown in Fig. 3 .This is calculated so as to keep the quantity of exchanged charge $(\mathrm{Q}$ (n)), which can be described as:

$\mathrm{Q}(\mathrm{n})=\sum_{\mathrm{i}=0}^{\mathrm{P}_{\mathrm{n}}} \mathrm{I}(\mathrm{n} \cdot \mathrm{i}) \cdot \Delta \mathrm{T}$

Where $\Delta \mathrm{T}$ the duration between two successive values of current. It, therefore, calculates the time $T(n)$ of a current level as follows:

$\mathrm{T}(\mathrm{n})=\sum_{\mathrm{i}=0}^{\mathrm{P}_{\mathrm{n}}} \mathrm{I}(\mathrm{n} \cdot \mathrm{i}) \cdot \frac{\Delta \mathrm{T}}{\mathrm{I}_{\mathrm{n}}}$

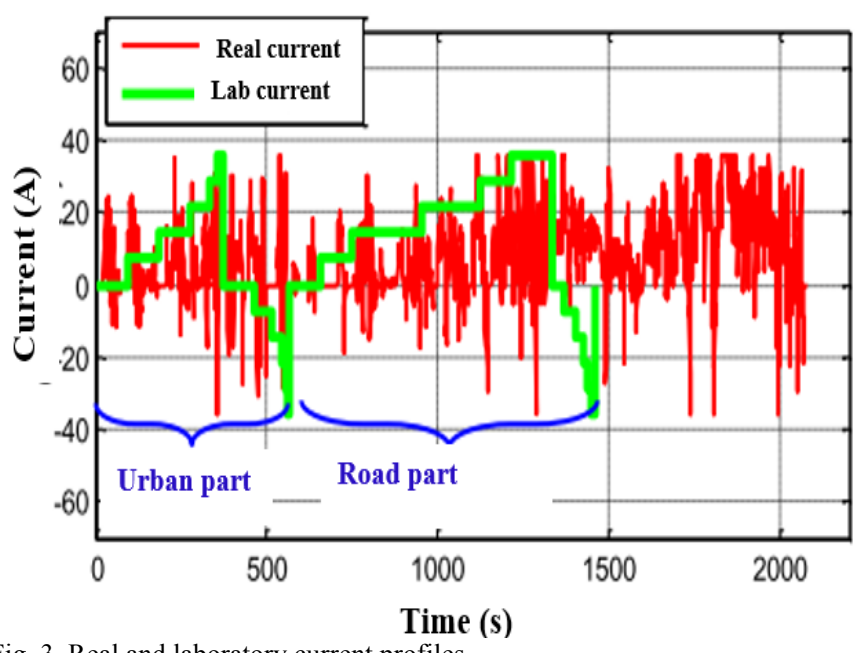

Fig. 3. Real and laboratory current profiles.

More details regarding the heuristic method of constraints classification are available in our previously work [36]. 


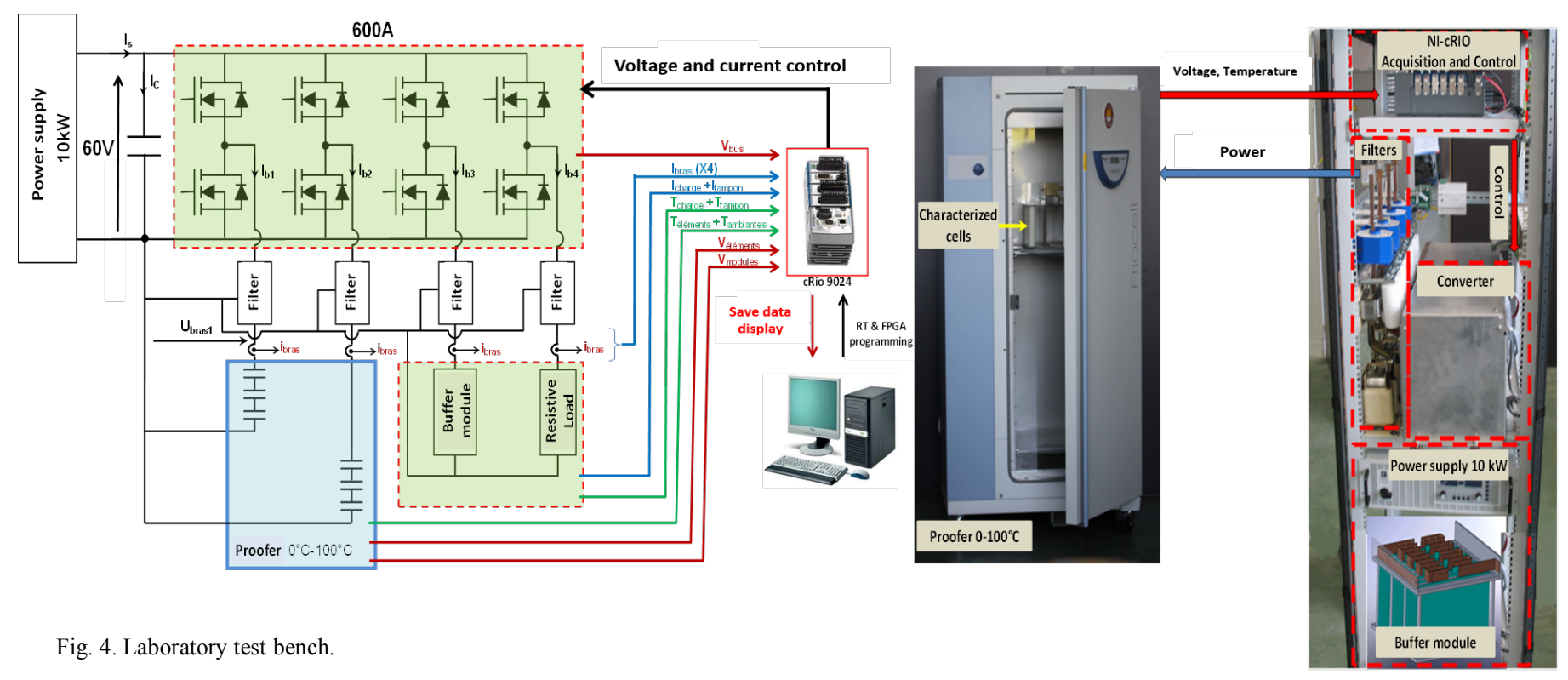

\section{B. Laboratory test bench}

The test system includes a laboratory test bench based on a dynamic charge / discharge power supply associated with a controlled climatic chamber. The latter is able to control the temperature within $\pm 0.02^{\circ} \mathrm{C}$ in the range from $0^{\circ} \mathrm{C}$ to $100{ }^{\circ} \mathrm{C}$.

The presented test bench has been developed in our laboratory for power cycling ageing, electric, and thermal characterization of energy storage components, such as batteries and supercapacitors. This bench is able to emulate the charge / discharge cycles under conditions similar to those used in real applications (electric or hybrid vehicle, energy storage, power filtering, uninterruptable power supplies... etc.). The developed test bench can track the behavior of a system under electrical constraints $24 \mathrm{~h} / 24 \mathrm{~h}$. Fig. 3 shows the diagram of the test bench, the power cycling is performed by controlling energy transit between the tested cells and buffer storage system. The latter is designed to store the energy of the tested cells during the discharge of these cells and restore this energy during the charging of these tested cells. For this, the capacitance of the buffer is 7 times higher than that of the tested cells. The energy dissipated during the cycling is compensated by a $10 \mathrm{~kW}$ power supply. In addition, a programmable resistive load of $9.6 \mathrm{~kW}$ is used to dissipate the excess power when required discharge of the tested cells.

To obtain a charge / discharge profile for the battery, a reversible four-leg power converter $(60 \mathrm{~V} / 600 \mathrm{~A})$ is used to guarantee the transit of energy between the tested cells and buffer storage system. A FPGA compact RIO NIcRIO9012/9014 real-time embedded module ensures the system control, test bench supervision, and transferring measured data to a PC. Therefore, the control loops are programmed in LabVIEW FPGA and the data acquisition is carried out at a sampling frequency of $1 \mathrm{kHz}$. The tested cells are placed in a climatic chamber in order to ensure their thermal homogeneity at the set temperature about of $25^{\circ} \mathrm{C}$.

\section{EXPERIMENTAL RESULTS}

Firstly, the test protocol focuses on parameters identification of ageing model for Li-ion battery cell. This test is based on the evaluation of the cycling impact on the battery lifetime by using two main phases:

- Cycling phase using the laboratory current profile gained from an electric vehicle application.

- Characterization phase during which measures the cycling impact on the evolution of the internal resistance and the energy capacity.

For electric power applications, the Li-ion battery is considered at the end-of-life when its performance is not guaranteed. This is defined in this case about to $20 \%$ loss of the energy capacity compared to its initial value [25], [37] . In this context, the laboratory current profile with a charge phase of constant-current / constant-voltage is applied consistently until the energy capacity of the Li-ion battery reaches $80 \%$ (end-of-life). The characterization protocol has been investigated under different operating conditions of the SOC and current values.

The temperature of the climatic chamber is adjusted in order to keep the external ambient temperature of about $25^{\circ} \mathrm{C}$ during characterization tests.

Fig. 5 (a) shows the laboratory current profile used for the characterization and ageing cycling tests of the Li-ion battery cell. As we can see from this figure, the ARTEMIS driving cycle (urban and road parts) is repeated seven times to achieve a vehicle range of $154 \mathrm{~km}$, and a constant-current/constantvoltage $(\mathrm{CC} / \mathrm{CV})$ charge protocol is used after each vehicle mission to charge the tested battery. Fig. 5 (b) illustrates the battery SOC evolution during one mission for the first and last use of the Li-ion battery. It can be seen in this figure, the difference on the battery SOC with a $20 \%$ of capacity loss between both cases for the same current profile.

Fig. 5 (c) shows the comparison of the modeling and experimental capacity fade of the Li-ion battery cell for a 
given current profile. It can be very clearly seen that the ageing behavior of the Li-ion battery can be simulated thanks to the proposed model with low values of relative error (less than $2 \%$, as shown in Fig. 5 (d)). Fig. 5 (e) illustrates a good matching between measured and simulated responses of the battery internal resistance. It can also be seen that the resistance increases up to $125 \%$ of its initial value and the end of resistive lifetime is reached after about 3600 cycles with an acceptable relative error less than $4 \%$ (see Fig. 5 (f)).

Fig. 6 (b) shows a comparison between the measured temperature of the Li-ion battery cell placed in the climatic chamber $\left(25^{\circ} \mathrm{C}\right)$ and the simulation of the thermal model for the same current profile (see Fig. 6 (a)). It can be seen that the reversible behavior of the battery heat transfer at the scale of a discharge/charge cycle is respected by the proposed model, with an acceptable relative error less than $4 \%$ (see Fig. 6 (c)). Moreover, these results confirm the dynamic behavior of the developed thermal model and the ability to take into account of different thermal phenomena inside the battery cell.

Fig. 7 (b) illustrates the experimental response of the battery voltage at the beginning of the battery use, and at the end-oflifetime $(-20 \% \mathrm{Cn})$ with the same current profile (see Fig. 7 (a)). It is obvious that the voltage of the battery in the case the end-of-lifetime decreases rapidly unlike the response of the battery at the mint condition. The difference between the two voltage responses becomes important for small values of the battery SOC, as shown in Fig. 7 (c).
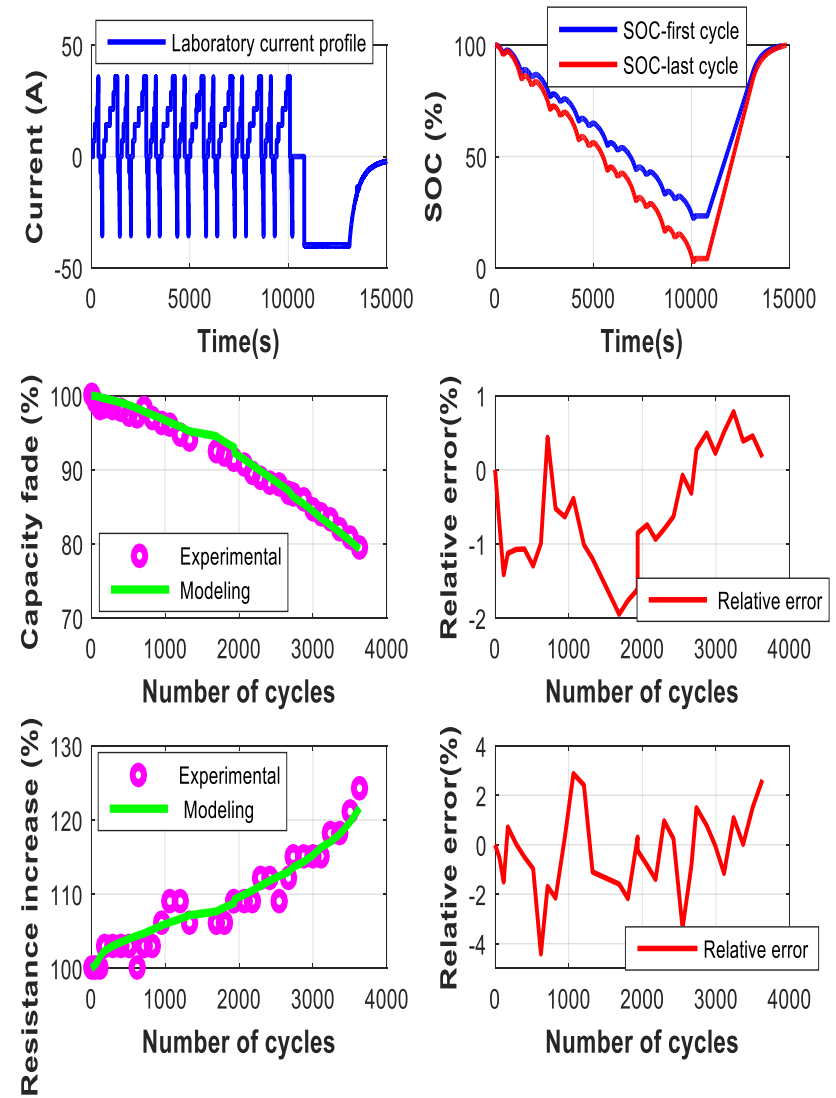

Fig. 5. (a) Laboratory current profile. (b) Battery SOC of first and last cycles. (c) Experimental and modeling responses of Li-ion battery capacity fade. (d) Relative error of capacity fade. (e) Experimental and modeling responses of Li-ion battery resistance increase. (f) Relative error of resistance increase.
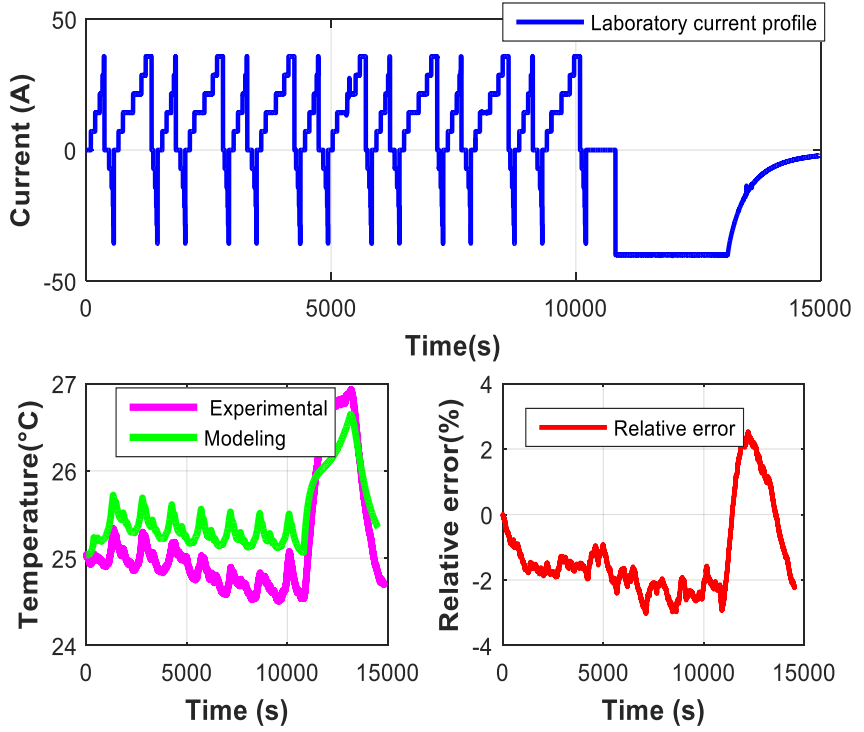

Fig. 6. (a) Laboratory current profile. (b) Experimental and modeling responses of Li-ion battery heat generation. (c) Relative error of battery heat generation.

In order to validate the parameters identification method under different operating conditions, we carried out a cycling test at the mint condition of the Li-ion battery cell. Fig. 8 (b) shows the evolution of the battery SOC for the same current profile (see Fig. 8 (a)). It can also be seen that the SOC varies between $20 \%$ and $100 \%$. As we can see from the Fig. 8 (c), the composition result illustrates that the battery behavior can be reproduced with a good agreement between the voltage response obtained using the dynamic battery model and the real voltage response of the battery cell. The relative error, as shown in Fig. 8 (d), is between -1 and 1\%, which confirms the best performance of the proposed model.
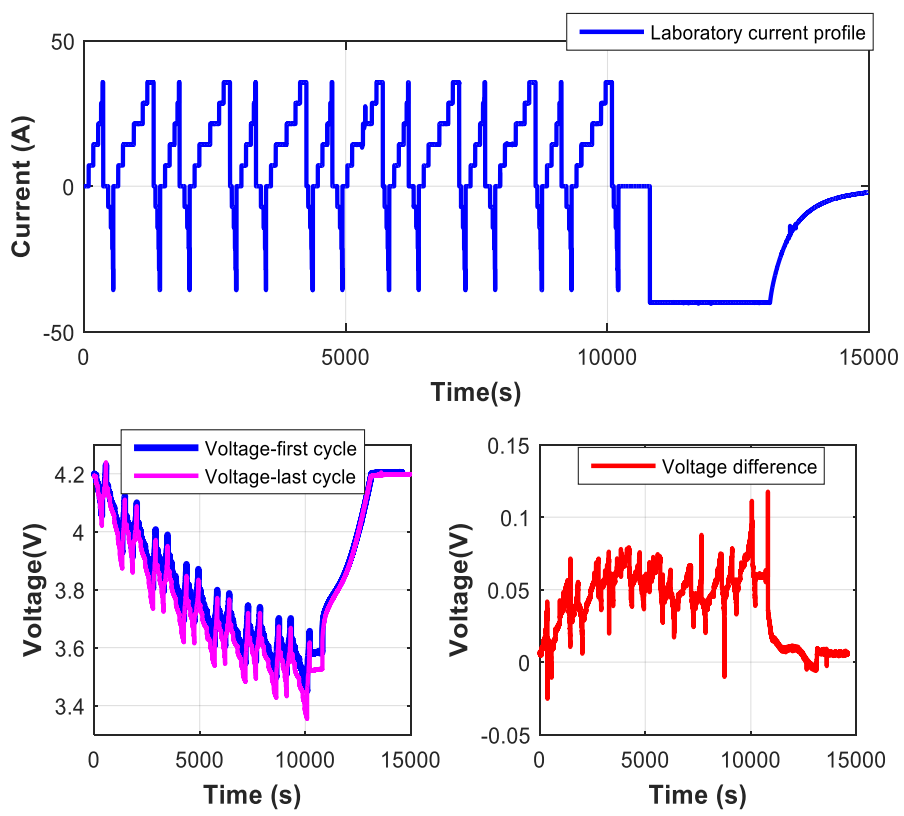

Fig. 7. (a) Laboratory current profile. (b) Battery voltage responses of first and last cycles. (c) Voltage difference between two responses. 

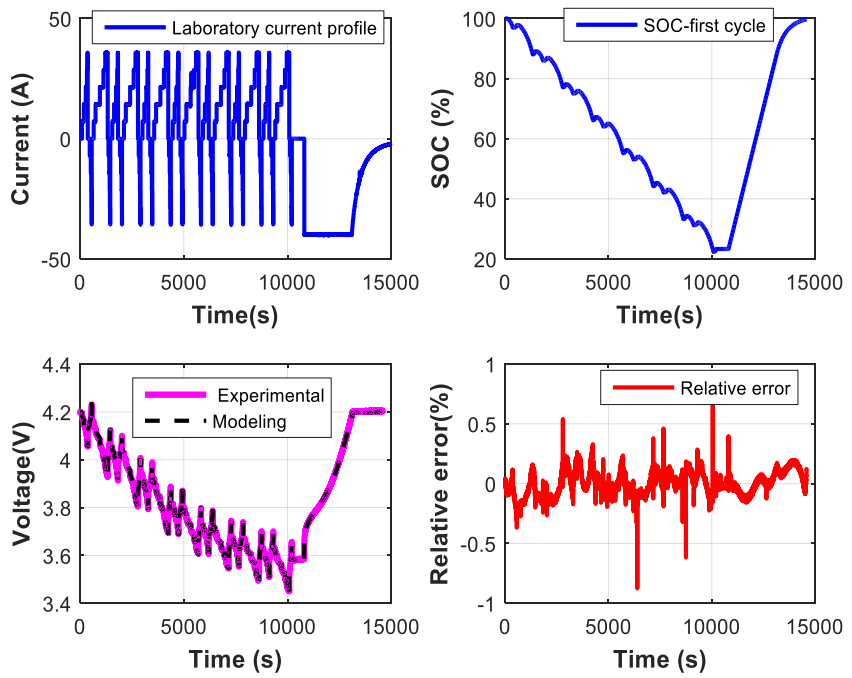

Fig. 8. (a) Laboratory current profile. (b) Battery SOC of the first cycle. (c) Experimental and modeling responses of battery voltage at the beginning of battery use. (c) Relative error of battery voltage.

The second cycling test has been performed at the battery end-of-lifetime (after 3600 cycles) to show the validation of the dynamic battery model under different operational conditions. The parameter values of the proposed model have been adapted taking into account the ageing parameters of $\left(C_{\text {bat }}=80 \%, R_{\Omega}=125 \%\right)$.

Fig. 9 (b) illustrates the battery SOC evolution with the same current profile (see Fig. 9 (a)). It can be very clearly seen that the SOC varies between a low value near zero and $100 \%$. The voltage responses of the Li-ion battery and the dynamic battery model are compared in Fig. 9 (c). It can be observed that there is no global divergence between both responses. This result confirms the best performance of the proposed model in view of its correspondence with the experimental response.
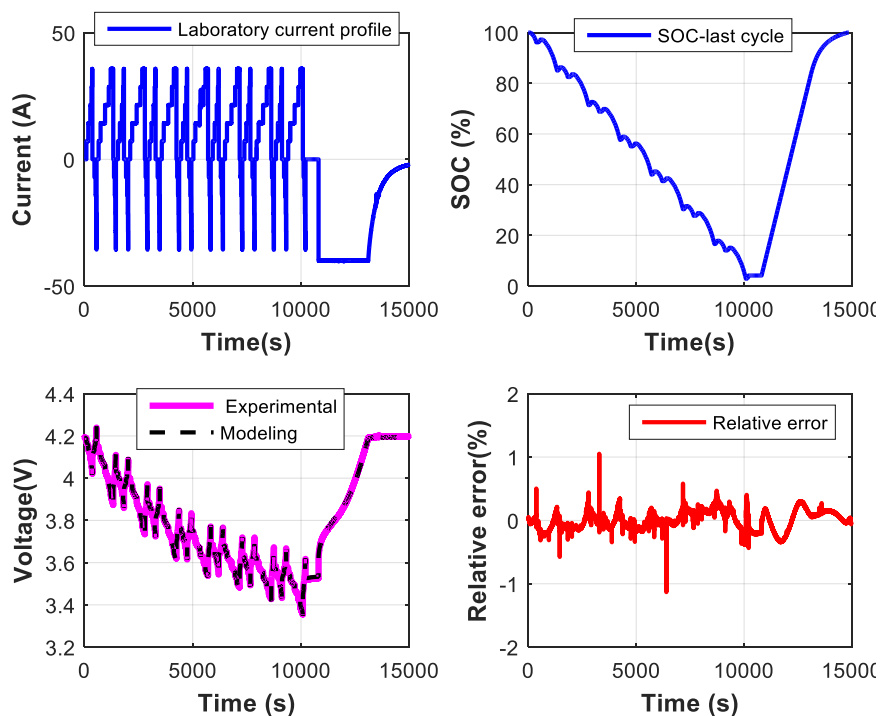

Fig. 9. (a) Laboratory current profile. (b) Battery SOC of the last cycle. (c) Experimental and modeling responses of battery voltage at the end-of-life ($20 \% \mathrm{Cn}$ ). (d) Relative error of battery voltage.
The precision of the proposed model is evaluated by the relative error between the modeling and the measured voltages. The maximum of this error, as shown in Fig. 9 (d), stays below $1 \%$ during the test.

\section{CONCLUSION}

This paper has illustrated how a dynamic model was used to accurately simulate the behavior of Li-ion batteries in electric vehicle applications. The proposed model integrates on a single algorithm, the electrical, thermal and ageing aspects occurring in a Li-ion battery cell. This approach of modeling allows us to reproduce the system behavior over long periods with a representation sufficiently fine. The dynamic battery model can be used to predict the capacity fade and internal resistance increases with a good trade-off between accuracy level and calculation time. The performance of this model has been investigated using a commercially available $40 \mathrm{Ah} \mathrm{Li-ion}$ battery cell under a given charge/discharge profile gained from an urban electric vehicle using the ARTEMIS driving cycle and $\mathrm{CC} / \mathrm{CV}$ charge protocol. The obtained results show that the dynamic battery model can simulate the electrical, thermal and ageing features with an acceptable relative error less than $1 \%, 4 \%$, and $2 \%$, respectively. The proposed modeling approach can further be used for other types of batteries and applications with appropriate parameters.

A detailed investigation of the thermal modeling of Li-ion batteries is in progress. Improving the dynamic model performance by including electric parameters change according to the temperature is a prospect.

\section{REFERENCES}

[1] R. Girard, "Electric car report What are the prospects for an eletric car inustry in canada and is this a real or false soulution for climate chnge?," Polaris Institute, Ottawa, 2011.

[2] J. Chen, "Creating the Clean Energy Economy Analysis of the Electric Vehicle Industry," International Economic Development Council, Washington, 2013.

[3] C. Shen, P. Shan, and T. Gao, "A Comprehensive Overview of Hybrid Electric Vehicles," Int. J. Veh. Technol., vol. 2011, pp. 1-7, 2011.

[4] M. Ortuzar, J. Moreno, and J. Dixon, "Ultracapacitor-Based Auxiliary Energy System for an Electric Vehicle: Implementation and Evaluation," IEEE Trans. Ind. Electron., vol. 54, no. 4, pp. 2147-2156, Aug. 2007.

[5] O. Konig, C. Hametner, G. Prochart, and S. Jakubek, "Battery Emulation for Power-HIL Using Local Model Networks and Robust Impedance Control," IEEE Trans. Ind. Electron., vol. 61, no. 2, pp. 943-955, Feb. 2014.

Z. Amjadi and S. S. Williamson, "Power-Electronics-Based Solutions for Plug-in Hybrid Electric Vehicle Energy Storage and Management Systems," IEEE Trans. Ind. Electron., vol. 57, no. 2, pp. 608-616, Feb. 2010.

P. Munoz-Condes, M. Gomez-Parra, C. Sancho, M. A. G. San Andres, F. J. Gonzalez-Fernandez, J. Carpio, and R. Guirado, "On Condition Maintenance Based on the Impedance Measurement for Traction Batteries: Development and Industrial Implementation," IEEE Trans. Ind. Electron., vol. 60, no. 7, pp. 2750-2759, Jul. 2013. T. Mesbahi, F. Khenfri, N. Rizoug, P. Bartholomeus, and P. Le Moigne, "Combined Optimal Sizing and Control of Li-Ion Battery/Supercapacitor Embedded Power Supply Using Hybrid Particle Swarm-Nelder-Mead Algorithm," IEEE Trans. Sustain. Energy, vol. 8, no. 1, pp. 59-73, Jan. 2017.

[9] G. Altemose, P. Hellermann, and T. Mazz, "Active cell balancing system using an isolated share bus for Li-Ion battery management: Focusing on satellite applications," 2011 IEEE Long Isl. Syst. Appl. Technol. Conf., pp. 1-7, May 2011. 
[10] L.-R. Chen, R. C. Hsu, and C.-S. Liu, "A Design of a GreyPredicted Li-Ion Battery Charge System," IEEE Trans. Ind. Electron., vol. 55, no. 10, pp. 3692-3701, Oct. 2008.

[11] T. Mesbahi, A. Ouari, T. Ghennam, E. M. Berkouk, N. Rizoug, N. Mesbahi, and M. Meradji, "A stand-alone wind power supply with a Li-ion battery energy storage system," Renew. Sustain. Energy Rev., vol. 40, pp. 204-213, Dec. 2014.

[12] J. Li, M. Mazzola, J. Gafford, and N. Younan, "A new parameter estimation algorithm for an electrical analogue battery model," 2012 Twenty-Seventh Annu. IEEE Appl. Power Electron. Conf. Expo., pp. 427-433, Feb. 2012.

[13] S. Bhide and T. Shim, "Novel Predictive Electric Li-Ion Battery Model Incorporating Thermal and Rate Factor Effects," IEEE Trans. Veh. Technol., vol. 60, no. 3, pp. 819-829, Mar. 2011.

[14] M. Einhorn, F. V. Conte, C. Kral, and J. Fleig, "Comparison, Selection, and Parameterization of Electrical Battery Models for Automotive Applications," IEEE Trans. Power Electron., vol. 28, no. 3, pp. 1429-1437, Mar. 2013.

[15] T. Mesbahi, F. Khenfri, N. Rizoug, K. Chaaban, P. Bartholome?s, and P. Le Moigne, "Dynamical modeling of Li-ion batteries for electric vehicle applications based on hybrid Particle SwarmNelder-Mead (PSO-NM) optimization algorithm," Electr. Power Syst. Res., vol. 131, 2016.

[16] G. K. Prasad and C. D. Rahn, "Model based identification of ageing parameters in lithium ion batteries," J. Power Sources, vol. 232, pp. 79-85, Jun. 2013.

[17] D. Riu, M. Montaru, and Y. Bultel, "Time domain simulation of Liion batteries using non-integer order equivalent electrical circuit," Commun. Nonlinear Sci. Numer. Simul., vol. 18, no. 6, pp. 14541462, Jun. 2013.

[18] M. Gholizadeh and F. R. Salmasi, "Estimation of State of Charge, Unknown Nonlinearities, and State of Health of a Lithium-Ion Battery Based on a Comprehensive Unobservable Model," IEEE Trans. Ind. Electron., vol. 61, no. 3, pp. 1335-1344, Mar. 2014.

[19] M. Uno and A. Kukita, "Cycle Life Evaluation Based on Accelerated Ageing Testing for Lithium-Ion Capacitors as Alternative to Rechargeable Batteries," IEEE Trans. Ind. Electron., vol. 63 , no. 3, pp. 1607-1617, 2016.

[20] M. Ecker, J. B. Gerschler, J. Vogel, S. Käbitz, F. Hust, P. Dechent, and D. U. Sauer, "Development of a lifetime prediction model for lithium-ion batteries based on extended accelerated ageing test data," J. Power Sources, vol. 215, pp. 248-257, Oct. 2012.

[21] Y. Zou, X. Hu, H. Ma, and S. E. Li, "Combined State of Charge and State of Health estimation over lithium-ion battery cell cycle lifespan for electric vehicles," J. Power Sources, vol. 273, pp. 793803, Jan. 2015.

[22] A. El Mejdoubi, A. Oukaour, H. Chaoui, H. Gualous, J. Sabor, and Y. Slamani, "State-of-Charge and State-of-Health Lithium-Ion Batteries' Diagnosis According to Surface Temperature Variation," IEEE Trans. Ind. Electron., vol. 63, no. 4, pp. 2391-2402, 2016.

[23] M. Gholizadeh and F. R. Salmasi, "Estimation of state of charge, unknown nonlinearities, and state of health of a lithium-ion battery based on a comprehensive unobservable model," IEEE Trans. Ind. Electron., vol. 61, no. 3, pp. 1335-1344, 2014.

[24] J. Jiang, Q. Liu, C. Zhang, and W. Zhang, "Evaluation of acceptable charging current of power Li-Ion batteries based on polarization characteristics," IEEE Trans. Ind. Electron., vol. 61, no. 12, pp. 6844-6851, 2014.

[25] A. Sidhu, A. Izadian, and S. Anwar, "Adaptive nonlinear modelbased fault diagnosis of li-ion batteries," IEEE Trans. Ind. Electron., vol. 62 , no. 2, pp. 1002-1011, 2015.

[26] T. Mesbahi, N. Rizoug, F. Khenfri, P. Bartholomeüs, and P. Le Moigne, "Dynamical modelling and emulation of Li-ion batteriessupercapacitors hybrid power supply for electric vehicle applications," IET Electr. Syst. Transp., pp. 1-9, Nov. 2016.

[27] J. Brand, Z. Zhang, and R. K. Agarwal, "Extraction of battery parameters of the equivalent circuit model using a multi-objective genetic algorithm," J. Power Sources, vol. 247, pp. 729-737, Feb. 2014.

[28] A. Cordoba-Arenas, S. Onori, and G. Rizzoni, “A control-oriented lithium-ion battery pack model for plug-in hybrid electric vehicle cycle-life studies and system design with consideration of health management," J. Power Sources, vol. 279, pp. 791-808, Dec. 2014.

[29] N. Devillers, M.-C. Péra, S. Jemei, F. Gustin, and D. Bienaimé, "Complementary characterization methods for Lithium-ion Polymer secondary battery modeling," Int. J. Electr. Power Energy Syst., vol. 67, pp. 168-178, May 2015.

[30] D.-H. Shin, J.-B. Jeong, T.-H. Kim, and H.-J. Kim, "Modeling of Lithium Battery Cells for Plug-In Hybrid Vehicles," J. Power Electron., vol. 13, no. 3, pp. 429-436, May 2013.

[31] M. T. Vakil Baghmisheh, M. Peimani, M. H. Sadeghi, M. M. Ettefagh, and A. F. Tabrizi, "A hybrid particle swarm-Nelder-Mead optimization method for crack detection in cantilever beams," Appl. Soft Comput., vol. 12, no. 8, pp. 2217-2226, Aug. 2012.

[32] "Kokam Li-ion batteries." [Online]. Available: http://www.kokam.com/.

[33] "Bolloré Bluecar," 2015. [Online]. Available: www.bluecar.fr.

[34] R. Sadoun, N. Rizoug, P. Bartholomeus, B. Barbedette, and P. Le Moigne, "Optimal sizing of hybrid supply for electric vehicle using Li-ion battery and supercapacitor," in 2011 IEEE Vehicle Power and Propulsion Conference, 2011, pp. 1-8.

[35] M. André, "The artemis European driving cycles for measuring car pollutant Emission," INRETS- LTE 0411, 2004.

[36] N. Rizoug, R. Sadoun, T. Mesbahi, P. Bartholumeus, and P. LeMoigne, "Ageing of high power Li-ion cells during real use of electric vehicles," IET Electr. Syst. Transp., vol. 7, no. 1, pp. 14-22, Mar. 2017.

[37] J. Guo, Z. Li, and M. Pecht, "A Bayesian approach for Li-Ion battery capacity fade modeling and cycles to failure prognostics," $J$. Power Sources, vol. 281, pp. 173-184, May 2015. 